\title{
PHYSICAL ACTIVITY LEVELS IN MILD AND MAJOR NEUROCOGNITIVE DISORDERS
}

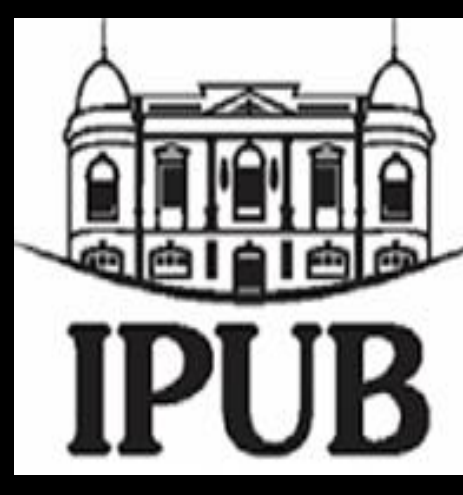

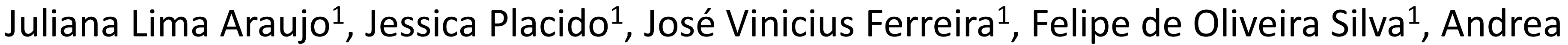
C. Deslandes ${ }^{1}$

\section{${ }^{1}$ Psychiatry Institute, Universidade Federal do Rio de Janeiro (UFRJ), Brazil}

\section{BACKGROUND AND AIMS}

The physical exercise is well-known for its protective effects on metabolic, cardiovascular and mental health. Due to the increase of the population over 60 years, prevalence of $\mathrm{MCl}$ and $A D$ is growing. Considering the relationship between sedentary behavior and increased prevalence in cognitive decline, it is necessary to recognize the physical activity levels in patients with neurocognitive disorders.

\section{OBJECTIVES}

To verify whether diagnostic of Mild Cognitive Impairment (MCl) and Alzheimer Disease (AD) can influence the level of physical activity.

\section{MATERIALS AND METHODS}

In a cross-sectional study, 79 seniors $(\mathrm{MCl}=18$, $A D=25$, Healthy=36) were evaluated. International Physical Activity Questionnaire (IPAQ) was applied to access physical activity levels and Mini-Mental State Examination (MMSE) was used to evaluate global cognitive function. Kruskal-Wallis Test and ANOVA Oneway were utilized to compare the groups and multiple regression to investigate the relationship between diagnosis and IPAQ.

\section{RESULTS}

All groups were different in IPAQ $\left(X^{2}=9.4\right.$; $p=0.009)$, showing a gradient impairment in levels of physical activity according the cognitive decline. As expected, age, schooling and global cognition were different between $A D$ and the other groups (Table1). Diagnostic predicts physical activity levels, even when controlled by age (Table2).

\begin{tabular}{|c|c|c|c|c|c|}
\hline & $\begin{array}{c}\text { Healthy } \\
(\mathrm{a}=36)\end{array}$ & $\begin{array}{c}\text { MCI } \\
(\mathrm{n}=18)\end{array}$ & $\underset{(n=25)}{A D}$ & $x^{2} / F$ & $\mathbf{p}$ \\
\hline Age (years) & $75.2=8.4$ & $77.2=6.6$ & $80 \pm 7.8$ & $8.8^{1}$ & $<0.001^{* * *}$ \\
\hline Schooling (years) & $12(4-29)$ & $16(3-20)$ & $11.5(1-23)$ & $13.2^{\circ}$ & $0.001^{* * *}$ \\
\hline IPAQ (MET/week) & $883.5(33-12.558)$ & $852(50-6.384)$ & $462(66-6.132)$ & $9.4^{\mathrm{b}}$ & $0.009^{*}$ \\
\hline MMSE (score) & $29(22-30)$ & $29(19-30)$ & $20(10-28)$ & $71.4^{b}$ & $<0,001^{* * *}$ \\
\hline
\end{tabular}

Table 2. Multiple regression models IPAQ Questionnaire

$\mathrm{R}^{2}$ adjusted $=0.112 \mathrm{p}=0.002$

\begin{tabular}{lccc} 
& $\mathrm{B}$ & $95 \% \mathrm{CI}$ & $\mathrm{p}$ \\
\hline Diagnostic & -375.50 & $-749.965,-1.503$ & 0.04 \\
Age & -47.5 & $-88.234,-6.872$ & 0.02 \\
\hline B - Unstandardized coefficients. CI - Confidence Interval. Level of significance $-\left({ }^{*} \mathrm{p} \leq .05\right)$
\end{tabular}

\section{CONCLUSIONS}

Patients with neurocognitive disorders are more sedentary even in the beginning of the disease, with $A D$ individuals achieve less than recommended by American College Sports and Medicine - ACSM (500-700 METs weekly) for health maintenance. Considering the protective effect of exercise in the brain, we strongly suggest that caregivers or members family encourage the elderly to do physical activity at least 150 minutes per week.

\section{REFERENCES}

Plácido, J., Ferreira, J. V., Oliveira, F. D., Sant'Anna, P., Monteiro-Junior, R. S., Laks, J., \& Deslandes, A. C. (2019). Association among 2-min step test, functional level and diagnosis of dementia. Dementia \& neuropsychologia, 13(1), 97-103.

Zanco, M., Placido, J., Marinho, V., Ferreira, J. V., Oliveira, F., Monteiro-Junior, R. S., ... \& Deslandes, A. (2018). Spatial Navigation in the Elderly with Alzheimer's Disease: A Cross-Sectional Study. Journal of Alzheimer's Disease, (Preprint), 1-12.

Groot, C., Hooghiemstra, A. M., Raijmakers, P. G. H. M., Van Berckel, B. N. M., Scheltens, P., Scherder, E. J. A., ... \& Ossenkoppele, R. (2016). The effect of physical activity on cognitive function in patients with dementia: a metaanalysis of randomized control trials. Ageing research reviews, 25, 13-23.

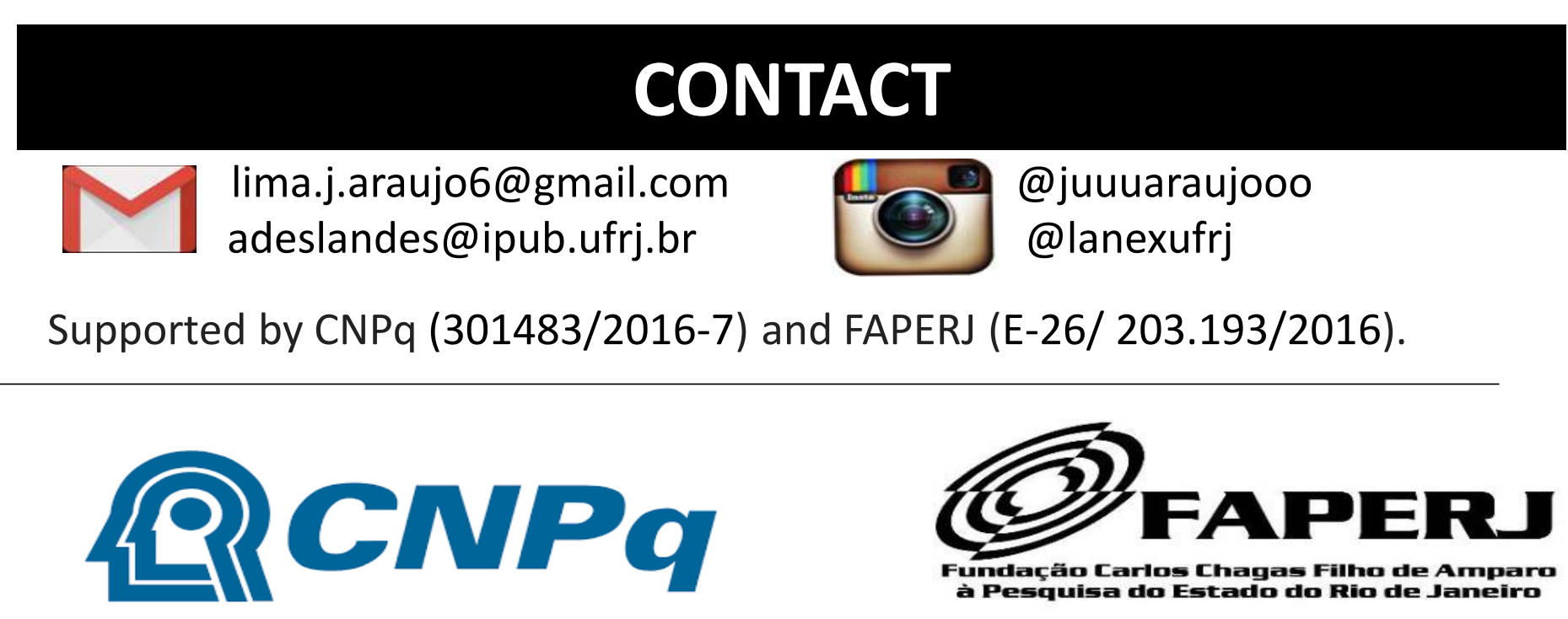

